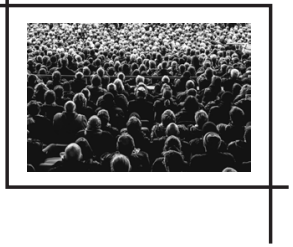

\title{
OLHARES DISTINTOS: A MULHER COM IMPEDIMENTO AUDITIVO NO CINEMA
}

\author{
Alessandra Furtado de Oliveira* \\ Maria Cristina Barbosa Mendes** \\ Ruth Maria Mariani Braz ${ }^{* * *}$ \\ Elaine Alves Leite**** \\ Sérgio Crespo Coelho da Silva Pinto*****
}

Resumo: 0 cinema torna-se um importante colaborador ao apresentar ao discente, que muitas vezes não tem a possibilidade de conhecer outros continentes e culturas, um universo novo, que transporta a sétima arte para a sala de aula. Nesse processo, professores apresentam novos conceitos e realidades e reforçam outros tantos. 0 presente artigo trata de uma abordagem que envolve a figura feminina com deficiência auditiva, considerando a história da língua de sinais, suas caracteristicas e importância. Esse trabalho visa a analisar como a figura feminina, de pessoas com impedimento auditivo, é abordada de forma diferente em três filmes: Babel (2007), A linguagem do coração (2014) e A forma da água (2017). Posteriormente, analisamos como a língua de sinais é um importante meio de comunicação legal - tanto dentro da comunidade surda quanto entre a comunidade surda e os não surdos. A pesquisa lançou mão de um levantamento bibliográfico, contemplado pelo estudo exploratório, com base em uma metodologia qualitativa. Os resultados evidenciaram que o cinema segue como um importante veículo de propagação de ideias e, por meio dele, podemos ver como a figura da pessoa com impedimento auditivo é retratada. As constantes produções de gênero dramático reforçam estereótipos de que essas pessoas são incapazes - quando devemos ter um novo olhar, que explore a potencialidade que há em cada um, com suas subjetividades. Por conseguinte, podemos concluir que cada pessoa é única em sua forma de agir: todos podem ser independentes, autônomos e devem ter suas diferenças respeitadas, inclusive no que diz respeito às singularidades linguísticas de minorias, com a valorização da comunicação plural destas com o mundo que as cerca.

Palavras-chave: Libras. Cinema. Surdez. Inclusão. Ensino.

\footnotetext{
* Mestranda em Diversidade e Inclusão pela Universidade Federal Fluminense (UFF). E-mail: afurtadodeoliveiranovaes@yahoo. com.br

** Mestra em Diversidade e Inclusão da Universidade Federal Fluminense (UFF). E-mail: mariacristinabarbosamendes@gmail.com

*** Doutora em Ciências e Biotecnologia e Educação. Universidade Federal Fluminense (UFF). E-mail: ruthmariani@yahoo.com.br

**** Mestranda em diversidade e Inclusão pela Universidade Federal Fluminense (UFF). E-mail: laneleite54@gmail.com

***** Doutor em Ciências da Computação pela Universidade Federal Fluminense (UFF). E-mail: screspo@id.uff.br
} 


\section{INTRODUÇÃO}

A língua de sinais foi criada por homens com o objetivo de se comunicarem: a sua criação não difere da de outras línguas, como a língua portuguesa. Considerando que a língua portuguesa surgiu do latim e teve contribuições de diversas outras até chegar à forma como a conhecemos hoje, lembramos que qualquer língua é viva e está diretamente relacionada com a sociedade na qual está inserida.

Assim como as línguas orais, portanto, as línguas de sinais também são vivas e não pertencem a um único grupo: são línguas de todos e para todos. Sofrem influências das interações sociais, sujeitam-se a regionalismos, modificam-se de modo contínuo, são múltiplas ao redor do mundo, agregam e intensificam-se com o passar dos anos.

Nesse contexto, a pessoa com impedimento auditivo foi vista com diferentes olhares, nos diferentes períodos históricos. Os registros na história demonstram que relações de dinheiro e pelo poder são constantes na maneira como podemos observar o mundo.

\footnotetext{
[...] Na sociedade romana, o percurso dos surdos não era diferente em relação aos Gregos, pois eram considerados imperfeitos para uma sociedade onde se cultivava a beleza física e intelectual. A literatura relata, no entanto, que, o fator econômico de algumas familias fazia com que alguns tivessem privilégios como Quintus Peduis, artista surdo, filho de cônsul romano, que obteve a autorização de César Augusto para desempenhar sua profissão de pintor (BRAZ, 2014, p. 16).
}

Durante muitos anos, até a Idade Média, acreditava-se que as pessoas com impedimento auditivo fossem imbecis: logo, não eram capazes de serem educáveis. Somente no século XVI foi admitido o fato de que as pessoas com impedimento auditivo poderiam aprender, segundo relatos de pedagogos que trabalharam com surdos, por meio de procedimentos pedagógicos específicos.

Braz (2014) menciona que Fray de Melchor Yebra, de Madri, escreveu um livro intitulado Refugium Infirmorum, no ano de 1593, e nele descreveu e ilustrou o alfabeto manual da época, confeccionado em madeira, para auxiliar as pessoas que não falavam na confissão.

0 Fray não criou o alfabeto, mas o utilizou e insistiu em divulgar o que João de Fidenza (1221-1274) fizera, o real autor deste instrumento, mais conhecido como San Buenaventura. 0 suposto conteúdo estava presente no trabalho Alphabetum religioso rumincipiendium, escrito há 300 anos (IVARS, 1920). Nesse mesmo século surgiu um monge beneditino em Madrid, Pedro Ponce de León (1520-1584), que desenvolveu o alfabeto manual (datilologia) e pode ser considerado o primeiro professor de surdos na história mundial (BERTHIER, 1873; CARVALHO, 2013). Ponce ensinava aos filhos dos nobres a ler, rezar e a falar para que 
pudessem defender as suas terras e os seus bens. De acordo com Carvalho (2013), na época "quem não conseguisse falar não teria quaisquer direitos perante a lei". Pablo Bonet (15791629) teve acesso às informações do ensino de Ponce através da família de Fernandez Velasco, que tinha tido pessoas surdas em sua família por várias gerações. Bonet contribuiu para o ensino dos surdos defendendo que, para estes aprendessem a ler, era necessário o recurso a imagens, introduzindo pela primeira vez neste domínio a pedagogia visual. Esse afirmou ainda no seu livro "Redução das Letras e Artes para Ensinar a Falar os Mudos", que o alfabeto manual já existia muito antes do seu tempo, contrariando os autores da época, que identificavam Poncé como o criador do alfabeto manual (BRAZ, 2014, p. 18).

Segundo Almeida e Almeida (2012), muitos trabalhos pedagógicos desenvolvidos com os surdos se perderam, pois não era comum os pedagogos divulgarem como estavam trabaIhando. Sabe-se, entretanto, que os alfabetos manuais foram muito usados na alfabetização dos surdos.

No século XVIII, o trabalho pedagógico com as pessoas com impedimento auditivo se dividia entre oralistas e gestualistas. Segundo Almeida e Almeida (2012), dentro das escolas e internatos para meninos era usada a língua de sinais. Entretanto, se algum discente fosse flagrado fazendo o uso da língua de sinais, haveria punição. Não existem registros sobre nenhuma punição, logo, não podemos afirmar se isso é verdade ou uma simples interpretação do autor.

Thomas Braidwood (1715-1806) abriu uma escola na Grã-Bretanha e, em 1755, Charles Michel L'Épée (1712-1789) criou a primeira escola para pessoas com perda auditiva na França - que mais tarde tornou-se o Instituto Nacional dos Surdos e Mudos de Paris. "Pierre Desloges (1779) foi o primeiro surdo a escrever um livro que informava que a Língua Gestual Francesa já existia mesmo antes de L'Épée abrir a sua escola. Assim, segundo ele, este não poderia ser considerado o pai da Língua Gestual Francesa" (BRAZ, 2014, p. 20).

Com a criação das escolas de língua de sinais/gestuais, ocorreram avanços por meio da divulgação dos estudos realizados por diferentes pessoas em diversos locais no mundo. Em Portugal, Jacob Rodrigues Pereira (1715-1780) criou a Casa Pia de Lisboa - instituto que funciona até hoje. Jacob modificou o alfabeto de Pablo Bonet (1579-1629). "Bonet contribuiu para o ensino dos surdos defendendo que, para que estes aprendessem a ler era necessário o recurso a imagens, introduzindo pela primeira vez neste domínio a pedagogia visual" (BRAZ, 2014, p. 19).

L'Épée observou como duas irmãs gêmeas surdas se comunicavam por meio de gestos e, desde então, passou a defender a língua de sinais como a língua de comunicação das pessoas com perdas auditivas.

0 método de L'Épée teve muito êxito no trabalho pedagógico com as pessoas com perda auditiva. Segundo Lacerda (1998), a língua de sinais é concebida como um idioma e tem 
parâmetros próprios, sendo veículo adequado para desenvolver o pensamento e a comunicação das pessoas com impedimento auditivo.

Em 1880, aconteceu o II Congresso Internacional, em Milão, preparado por oralistas, que mostraram a eficiência do método - criticavam, assim, o método gestual na educação das pessoas com impedimento auditivo. Acreditava-se que o uso dos gestos afastaria os usuários da aprendizagem da língua oral, tese defendida por Alexandre Graham Bell (1847-1922), cientista, inventor e fonoaudiólogo. Graham Bell investiu muito tempo da sua vida em pesquisas voltadas à investigação do som e a experiências com aparelhos auriculares (BRAZ, 2014).

A educação para surdos no Brasil foi iniciada por Edouard Huet (1822-1882). Ele perdeu a audição aos 12 anos, frequentou o Instituto de Paris e, quando se tornou mestre, foi trazido para o Brasil pelo imperador dom Pedro II, que idealizava uma escola de acordo com o modelo europeu.

Edouard Huet foi responsável pelo Instituto dos Surdos-Mudos, fundado em 1857, hoje chamado de Instituto Nacional de Educação de Surdos (Ines). Os discentes vieram de vários lugares do Brasil para estudar na escola liderada pelo mestre francês e, posteriormente, por Frei do Carmo (CARVALHO, 2013).

Em 1987 foi criada a Federação Nacional de Educação e Integração dos Surdos (Feneis), com sede no Rio de Janeiro: uma entidade filantrópica que se preocupa com a defesa de políticas linguísticas, além de ser um espaço de socialização dos surdos. Conforme destaca Lacerda (1998, p. 71):

\begin{abstract}
A língua de sinais é considerada a mais adaptada à pessoa surda, por contar com a integridade do canal visual gestual. Porque as interações podem fluir, a criança surda é exposta, então, o mais cedo possivel, à língua de sinais, aprendendo a sinalizar tão rapidamente quanto as crianças ouvintes aprendem a falar. Ao sinalizar, a criança desenvolve sua capacidade e sua competência linguística, numa língua que Ihe servirá depois para aprender a língua falada, do grupo majoritário, como segunda língua, tornando-se bilíngue, numa modalidade de bilinguismo sucessivo.
\end{abstract}

Por meio da educação bilingue, a criança com impedimento auditivo desenvolve suas habilidades cognitivo-linguísticas, a fim de ampliar uma relação com os ouvintes, tendo acesso à língua de sinais e à língua majoritária.

Ao falar da importância da identidade nas crianças com perdas auditivas, Dizeu e Caporalli (2005, p. 593) afirmam que "a criança irá construir sua realidade social e descobrir a si própria pela comunicação, ou seja, por meio das interações ela passa a se perceber e se identificar com seus pares". É de suma importância que essas crianças estejam em contato com a comunidade local, para que elas possam se socializar diante das vivências sociais e de estímulos diferentes. 
0 cinema tem sido uma ferramenta que, entre suas múltiplas funções, apresenta as de entreter, propor reflexões e difundir ideias, servindo como importante recurso em sala de aula para a renovação de valores: nesse caso específico, a valorização da pessoa com perda auditiva. Por isso, com o passar do tempo, a chamada sétima arte consagrou uma trajetória que também tem caráter educativo.

Por meio desse veículo, podemos perceber pautas que envolvem tabus, pensamentos ideológicos, questões nacionalistas, meandros da psiquê, sucessos, fracassos, análises diferentes de um mesmo acontecimento (LARRUSCAIN; OLIVEIRA, 2011).

Todas essas questões podem ser muito bem aproveitadas e servir de subsídios para fomentar debates, despertando uma curiosidade para além do objeto a ser abordado na sala de aula, pois, além de ser um recurso muito atraente, sabemos que o cinema acaba funcionando como uma teia social, em que as interações entre os pares acabam por influenciar toda pessoa que assiste a uma determinada produção. 0 cinema pode ditar regras sociais, promover reflexões, influenciar a moda e ditar regras de conduta.

Dai a importância dos estudos feministas de cinema, que vêm ganhando força ao analisarem não apenas os personagens femininos retratados nas produções, como também a participação feminina na produção, distribuição e exibição de filmes. De acordo com Costa (2019), apenas a partir dos anos 1990 é que a academia começou a pesquisar sistematicamente essas mulheres: a intensificação do trabalho de pesquisadoras e pesquisadores mostrou que havia uma atividade feminina escondida.

Sendo assim, é muito importante analisar as formas como são abordadas as pessoas com deficiência pela sétima arte, sobretudo as mulheres com deficiência. A partir daí, podemos refletir sobre o tratamento dispensado a elas: se condiz com a realidade, se pode nos trazer novas reflexões sobre o papel relevante dessa parcela para a sociedade ou se reforça rótulos que merecem questionamentos.

A fim de responder à questão da investigação, o objetivo geral do trabalho é analisar como a figura feminina, de pessoas com deficiência auditiva, é abordada segundo os seguintes filmes: Babel (2007), A linguagem do coração (2014) e A forma da água (2017), e como essa análise pode contribuir para o debate em sala de aula sobre mulheres com surdez.

\section{METODOLOGIA}

Como encaminhamento metodológico, emprega-se um levantamento bibliográfico na base científica da Web of Science, com as palavras-chaves: "Sign Language", "Movie","Deafness", "Inclusion", "Teaching", e encontramos: 
Figura 1 Pesquisa na base Web of Science sem restrição das áreas de conhecimento

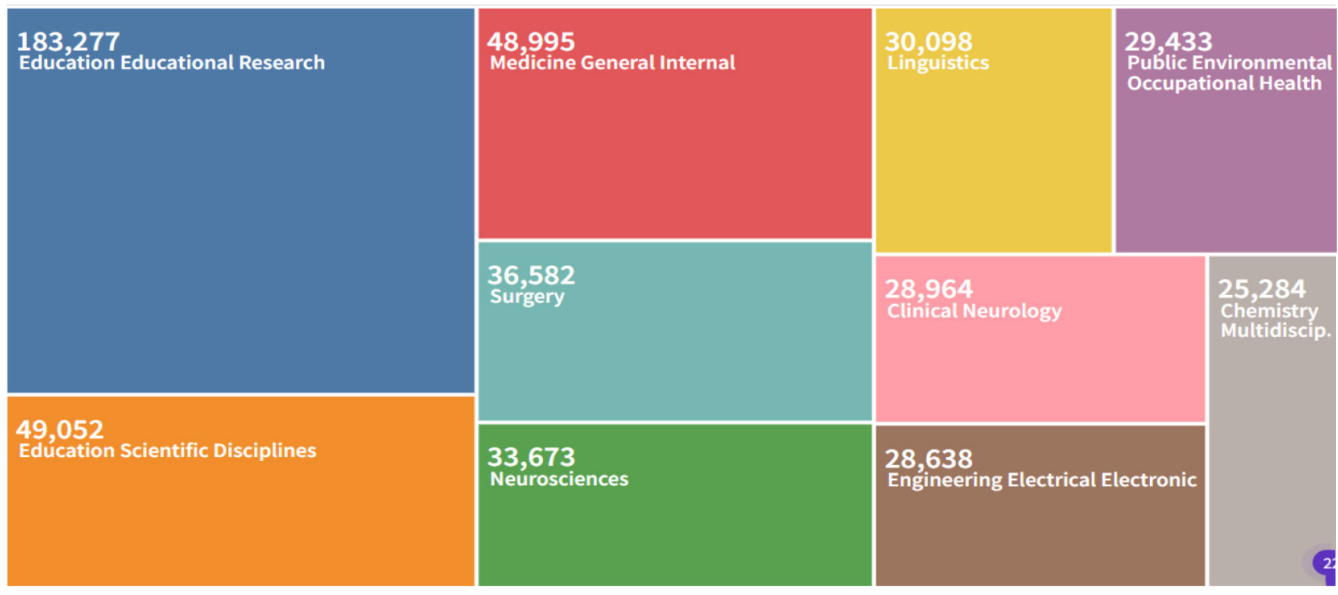

Fonte: Elaborada pelos autores.

Utilizamos as springs, selecionamos os artigos dos últimos cinco anos nas áreas de educação especial e na área de educação e encontramos 251 artigos.

Figura 2 Número de artigos nas áreas Education Educational Research

\section{e Education Special}
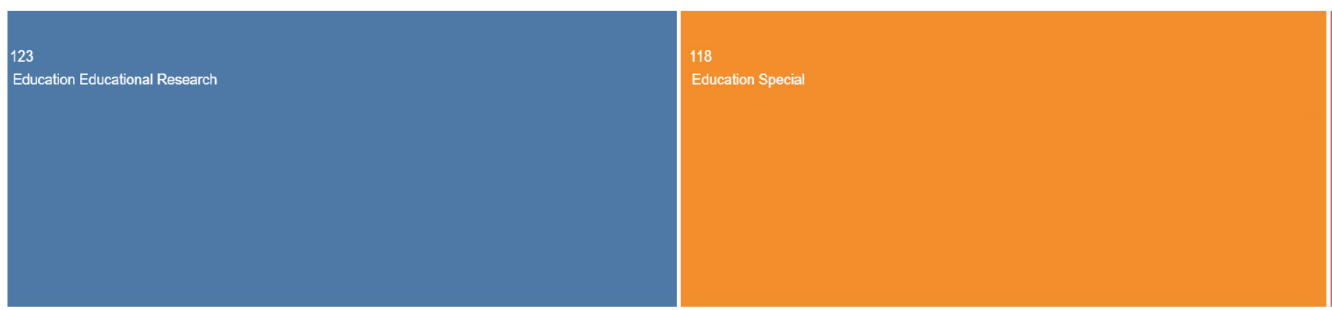

Fonte: Elaborada pelos autores.

Partimos então para a análise dos títulos e dos resumos dos artigos e realizamos um estudo exploratório, a partir de uma narrativa qualitativa. A partir dos temas já trabalhados e da constatação de menor produção relacionada ao tema do presente artigo, passamos à etapa seguinte, a análise da figura feminina com deficiência auditiva em três filmes. Os filmes escolhidos, para efeito de comparação, estavam disponiveis nas plataformas Globoplay e Netflix. Os demais textos acadêmicos foram encontrados no Google Acadêmico, na biblioteca de produções acadêmicas SciElo e nos periódicos da Coordenação de Aperfeiçoamento de Pessoal de Nivel Superior (Capes). 


\section{RESULTADOS E DISCUSSÃO}

Antes de falarmos das características da língua de sinais, é de suma importância estabelecer a diferença entre língua e linguagem. De acordo com Saussure (1987), a língua é parte determinada, essencial da linguagem, produto social da faculdade da linguagem para o exercício dessa faculdade pelos indivíduos de uma comunidade.

A linguagem tem valor semiótico, como nos falam Dizeu e Caporalli (2005, p. 586): "é nela que o pensamento do indivíduo é constituído". A linguagem pertence ao sujeito mesmo quando ele não está se comunicando. Ela está relacionada com a forma como o sujeito percebe o mundo à sua volta.

A língua de sinais não é universal, já que a língua difere entre as nacionalidades e entre as regionalidades. Podemos, inclusive, fazer uma relação com a língua portuguesa, que tem suas variações linguísticas diafásicas, diatópicas, históricas: a língua brasileira de sinais (Libras) também irá se diferenciar nos seus sinais de acordo com as variações linguísticas e nacionalidade.

A Libras foi reconhecida pela Lei n. 10.436, de 24 de abril de 2002, como meio legal de comunicação e expressão, in verbis: entende-se como Libras a forma de comunicação e expressão em que o sistema linguístico de natureza visual-motora, com estrutura gramatical própria constitui um sistema de transmissão de ideias e fatos, oriundos de comunidades de pessoas surdas do Brasil.

Segundo Uzan, Oliveira e Leon (2008), a Libras é utilizada pela maioria das pessoas com impedimento auditivo no Brasil. É considerada a primeira língua, sendo a língua portuguesa sua segunda língua de instrução nas escolas. É importante dizer que ela apresenta muitas semelhanças com a língua de sinais francesa, pois baseou-se nela.

A Libras tem gramática própria, assim como outras línguas, logo apresenta componentes fonológicos, morfológicos, sintáticos e semânticos específicos. Os sinais manuais e não manuais da Libras são descritos por Uzan, Oliveira e Leon (2008) como "gramática" especifica: a posição e o movimento da mão, o ponto de articulação do sinal, isto é, no corpo ou espaço de sinalização, a orientação e as expressões faciais ou corporais.

Isso posto, é possivel questionar: e no cinema? Como podemos encontrar as línguas gestuais? Há o reconhecimento da língua? Há confusão com a linguagem? Existe acessibilidade ou divulgação dessa forma de comunicação?

Historicamente, vale lembrar que o cinematógrafo foi inventado na França pelos irmãos Louis e Auguste Lumière em 1895. No dia 28 de dezembro daquele ano, eles fizeram uma projeção pública no Teatro Eden (La Ciotat), que fica no sudoeste da França e ainda existe. 0 filme tinha cerca de 40 minutos e mostrava o trem chegando à estação dessa mesma cidade, além de pessoas embarcando e desembarcando. Há relatos de que parte da população debandou diante do que viu, estarrecida: a máquina se aproximando e movimentando-se diante deles na tela. 
0 cinema foi uma invenção que, dentro das inovações da Revolução Industrial, contribuiu por ser um veículo difusor de ideias, feitos históricos, tendências da moda e entretenimento.

Utilizando todos os recursos cinematográficos, podemos explorar vários quesitos diferentes, tais como: a fotografia, a produção de época, a trilha sonora e a densidade do seu roteiro.

Dentro dessa proposta, buscamos analisar, de forma comparativa e considerando o que cada uma dessas películas propõe, três obras cinematográficas que abordam mulheres surdas e os estereótipos que cada uma dessas versões busca consolidar pela forma como essas personagens são apresentadas: como fazem sua comunicação com o mundo e como o uso da língua de sinais serve como grande facilitador dessa empreitada.

Os filmes analisados foram: Babel (2007), de Alejandro González Iñárritu; A linguagem do coração (2014), de Jean-Pierre Améris e A forma da água (2017), de Guilhermo del Toro.

Como citamos na introdução, o cinema também tentou caracterizar diferentes tendências de como retratar a pessoa com deficiência na história mundial. Segundo Albuquerque (2008), em um primeiro momento, logo no seu início - fins do século XIX e início do XX -, há uma forma caricata. Isso se explica porque, nessa época, era comum as pessoas simularem deficiências para pedir dinheiro nas ruas, principalmente em Nova York.

Em um segundo momento, temos os chamados freak shows, ou show de horrores, que expunham a deficiência com o intuito de chocar e despertar a curiosidade das pessoas. Em um terceiro momento, que está inserido na segunda metade do século $X X$, temos os deficientes como vilões, que, por não serem considerados "normais", eram pessoas desequilibradas, revoltadas e que queriam externar a sua raiva para o mundo. No quarto momento, que corresponde ao periodo após a Segunda Guerra Mundial, há o deficiente como herói, vinculando sua imagem à de muitos mutilados pelas batalhas. Como quinto e último momento, que tem início nas últimas décadas do século XX e estende-se aos dias atuais, percebemos que está em voga a ideia de retratar a pessoa com deficiência como alguém que vive um drama, ou com ele mesmo ou com aquilo que o cerca.

É importante salientar que, dos filmes que abordam pessoas com deficiência, a maioria trata da deficiência auditiva (AMARAL; MONTEIRO, 2016a, 2016b). Isso pode ser explicado pelo fato de a comunidade surda ter conseguido, por meio de muita luta, garantir direitos que Ihes trouxeram maior visibilidade.

No Brasil, um grande avanço nesse sentido foi a obrigatoriedade da disciplina de Libras em cursos de formação inicial de professores e de Fonoaudiologia. Paralelamente, ainda é pequena a produção audiovisual nacional com janelas de Libras.

Analisando as três obras escolhidas - Babel, A linguagem do coração e A forma da água-, notamos um componente que perpassa nos três títulos e que é muito recorrente quando se trata da abordagem de pessoas com deficiência: o drama. Embora as histórias se passem em contextos e épocas bem diferentes, o drama é o fio condutor dos três filmes. 
Em Babel (2007), temos um filme atual, que trata de multiculturalismo, no qual histórias em diferentes lugares do mundo se cruzam por um elemento comum: uma arma.

Em uma dessas histórias, uma garota asiática com impedimento auditivo vive um drama pessoal. Ela perde a mãe, tem uma relação complicada com o pai e não se encaixa muito bem na sociedade. Sabe usar a língua de sinais/gestuais de seu pai, mas prefere fazer uso de um caderninho, no qual escreve o que quer para se comunicar com os outros, o que demonstra uma certa relutância, uma resistência em se reconhecer como seus iguais.

No filme, Chieko, a personagem surda, embora seja bem-aceita pelo grupo da escola, é rejeitada por um grupo de meninos e vira chacota quando descobrem que ela é uma pessoa com perda auditiva. Essa jovem manifesta interesse em perder a virgindade e a forma que usa para tentar fazer isso, ao longo do filme, pode chocar quem ela assedia. É possivel questionar se o deficiente não tem vida sexual e se a cada investida, sem sucesso, o espectador desenvolve um olhar de piedade para com a personagem rejeitada. É como se a deficiência fosse uma barreira para sua concretização de uma vida "normal" e feliz, como se a sua deficiência fosse um transtorno para a sua família. É um fato pouco comum explorar o viés da sexualidade do surdo, tema pouco abordado no cinema. A autonomia dos surdos e a independência do núcleo familiar também são temas latentes.

No filme A linguagem do coração (2014), que está inserido no gênero biografia/drama, vimos a personagem central, Marie, como um "estorvo" para a família, que nunca a conseguiu calçar, tampouco pentear seus cabelos.

No início do filme o pai tenta, sem sucesso, deixar Marie em um convento que cuidava de crianças com perda auditiva. Para transportá-la com segurança, ele improvisa uma corda, fazendo as vezes de um cinto de segurança, para evitar que ela caia nos solavancos da estrada, já que fazem esse trajeto de carroça.

Nesse início é mostrado o sacrifício que seus progenitores fazem e como o cotidiano é desgastante, a ponto de procurarem deixá-la no convento e, diante da recusa, cogitarem a possibilidade de levá-la para um manicômio. No filme, a personagem se comporta "feito um animal": reage com muita agressividade aos estímulos externos e reluta muito em aceitar comportamentos dentro do padrão esperado pelas outras meninas da instituição.

A madre superiora, em dado momento, reforça a imagem que muitas vezes vemos no inconsciente coletivo de que a menina não tem inteligência e por isso não vai aprender como as demais internas - como se o fato de ela ser cega e surda a tornasse incapaz, a madre não percebe que a ela nunca foi dada a possiblidade de trabalhar suas potencialidades, já que a ela nunca the ensinaram coisa alguma.

A língua de sinais é usada o tempo todo tanto na comunicação entre as freiras e as internas quanto entre as freiras umas com as outras. Embora o filme se passe na França, no século XIX, percebe-se que as freiras tentavam exercer a inclusão o tempo todo. No horário das refeições, por exemplo, enquanto uma freira lia passagens da Biblia, outra fazia as vezes 
de intérprete de sinais ao seu lado. Aos poucos, a tutora de Marie, Marguerite, consegue iniciá-la na língua de sinais, ela consegue se "redimir" e passa então a uma fase de docilidade, autonomia e produtividade. Podemos perceber a importância da língua de sinais como mecanismo de comunicação das internas com o mundo que as cerca.

É possivel cogitar uma alusão do nome do filme ao fato de muitas das configurações que fazemos na língua dos sinais serem direcionadas do peito para fora, onde o nosso coração estaria alojado. Nessa película vemos a personagem central viver um drama social (a dificuldade de inserção no mundo, o abandono dos pais), seguido de outro, psicológico (o medo do novo, a rejeição das internas).

Já no filme A forma da água (2017), percebemos que, embora seja ainda um drama, gênero muito recorrente quando se propõe a falar sobre pessoas com deficiência, a personagem é independente e não aparenta carregar nenhum drama pessoal. Ela tem amigos, um emprego, se comunica por meio da língua de sinais. 0 nome do filme fala de um elemento que é mutável e resiliente, caracteristicas semelhantes às da personagem central.

No contexto do filme, ambientado na década de 1960, embora na época fosse uma constante retratar os deficientes como pessoas revoltadas com sua condição e querendo se vingar do mundo - vide A ilha do Tesouro (1950) e 007 - Contra o satânico Dr. No (1962) -, percebemos que o diretor refuta esse estereótipo e constrói uma personagem, Elisa Espósito, bem resolvida e independente. Porém, reforça o indivíduo deficiente como dócil e inocente, a ponto de se apaixonar por um ser aquático estranho, talvez como ela se identifique diante dos cidadãos ditos "normais".

Nas três obras selecionadas, as mulheres surdas são personagens de destaque. Poderíamos analisar a pluralidade da surdez entre as personagens: (i) como elas cresceram e se desenvolveram a partir da diferença de comunicação; (ii) como elas reconhecem ou não a comunicação por sinais; (iii) como elas se sentem enquanto pessoas com impedimento auditivo; e (iv) como elas interpretam a si e ao mundo ouvinte que as cerca.

A beleza do cinema associado ao ensino subjaz nos questionamentos que o filme pode trazer para a sala de aula, cabendo ao professor nortear debates relacionados às pessoas com deficiência, ao impedimento auditivo, à forma como a sociedade enxerga esse grupo e a como os discentes se veem inspirados pelas obras destacadas.

Assim, os conceitos sobre as pessoas com deficiências são construídos por meio do contexto histórico e devemos quebrar esse paradigma trazendo valores para onde a diversidade humana esteja presente.

\section{CONSIDERAÇÕES FINAIS}

Por muito tempo acreditou-se que as pessoas com impedimento auditivo não apresentavam nenhuma forma de comunicação ou linguagem. De fato, a língua de sinais é diferente 
de oralizar, e podemos fazer uso das linguagens para nos comunicar por diferentes maneiras: visual, auditiva, gestual, sonora, pictórica - contanto que haja comunicação efetiva e respeito à diversidade.

Ainda há muito a fazer no que tange aos direitos das pessoas com perdas auditivas, principalmente em relação ao processo de escolarização desse público-alvo. Precisamos de empatia, do rompimento de barreiras atitudinais e de políticas públicas consolidadas em ações que permitam seu cumprimento de fato. Medidas como essas irão favorecer a inclusão e permitir que pessoas com deficiência usufruam de todos os seus direitos.

Diante do exposto, é possivel concluir que as abordagens de educação para surdos se complementam, cada uma com seus pontos positivos e negativos, e que, juntas, abrem espaços para caminhos educacionais promissores, a fim de favorecer o desenvolvimento das pessoas com impedimento auditivo e situá-las como cidadãs plenas em nossa sociedade.

0 gênero fílmico mais comum para retratar pessoas com deficiência é o drama, e isso só reforça alguns estereótipos que acabam por confirmar a percepção do público de pessoas com deficiência como dependentes e incapazes. 0 cinema, com seu poder de propagação de ideias e reflexões, deve contribuir de forma que esse olhar seja modificado para o grande público.

A língua de sinais/gestuais é uma importante ferramenta para a inclusão da pessoa com impedimento auditivo na sociedade. 0 respeito às singularidades linguísticas dessa minoria deve ser defendido em qualquer segmento, pois auxilia a comunicação, valorizando a independência e a autonomia.

\section{Different looks: the woman with hearing impairment at the movies}

Abstract: Cinema becomes an important collaborator when presenting to the student - who often do not have the possibility of getting to know other continents and cultures, a new universe, which transports the seventh art to the classroom. In this process, teachers present new concepts and realities and reinforce many others. This article deals with an approach that involves the female figure, with hearing loss, considering the history of sign language, its characteristics and importance. This work aims to analyze how the female figure, of people with hearing impairment, is approached differently in three films: Babel (2007), The language of the heart (2014) and The shape of water (2017). We then looked at how sign language is an important means of legal communication - both within the deaf community and between the deaf community and non-deaf people. The research made use of a bibliographical survey, contemplated by the exploratory study, from a qualitative methodology. The results showed that cinema continues to be an important vehicle for the propagation of ideas and through it, we can see how the figure of the person with hearing impairment is portrayed. The constant productions of dramatic genre reinforce stereotypes that these people are incapable - when we must have a new look, which explores the potential that exists in each one, with their subjectivities. Therefore, we can conclude that each person is unique in their way of 
Alessandra Furtado de Oliveira, Maria Cristina Barbosa Mendes, Ruth Maria Mariani Braz, Elaine Alves Leite, Sérgio Crespo Coelho da Silva Pinto

acting: everyone can be independent, autonomous and must have their differences respected, including about the linguistic singularities of minorities, with the appreciation of their plural communication with the world that about.

Keywords: Sign language. Movie theater. Deafness. Inclusion. Teaching.

\section{REFERÊNCIAS}

007 CONTRA O SATÂNICO DR. NO. Direção: Tence Young. Produção: Harry Saltzman, Albert R. Broccoli. Intérpretes: Sean Connery, Ursula Andress, Joseph Wiseman, Jack Lord, Bernard Lee. Los Angeles: MGM, 1962. 1DVD (110 min), color.

A FORMA DA ÁGUA. Direção: Guilhermo del Toro. Los Angeles: 20th Century Fox; Miami: Bull Productions, 2017. 1 DVD (123 min), color.

A ILHA DO TESOURO. Direção: Byron Haskin. Intérpretes: Bobby Driscoll, Robert Newton, Basil Sydney, Walter Fitzgerald, Denis O'Dea, Finlay Currie, Ralph Truman, Geoffrey Keen, Geoffrey Wilkinson, John Laurie, Francis de Wolff, David Davies, John Gregson, Andrew Blackett, William Devlin, Howard Douglas, Harry Locke, Sam Kydd, Stephen Jack, Harold Jamieson, Diarmuid Kelly, Patrick Troughton. Burbank, Califórnia: Walt Disney Studios, 1950. 1 DVD (88 $\mathrm{min})$, color.

A LINGUAGEM DO CORAÇÃO. Direção: Jean-Pierre Améris. Intérpretes: Elenco: Isabelle Carré, Ariana Rivoire, Brigitte Catillon, Noemie Churlet. França: Imovision, 2014. 1 DVD (95 min), color.

ALBUQUERQUE, M. A. de. A pessoa com deficiência e suas representações no cinema brasileiro. 2008. 84f. Dissertação (Mestrado em Comunicação) - Faculdade de Comunicação Social, Universidade do Estado do Rio de Janeiro, Rio de Janeiro, 2008.

ALMEIDA, M. P. D.; ALMEIDA, M. E. História de Libras: caracteristica e sua estrutura. Revista Philologus, Rio de Janeiro, ano 18, n. 54, p. 315-327, 2012. Disponivel em: http://www.filologia.org.br/rph/AN018/54SUP/031.pdf. Acesso em: 30 mar. 2021.

AMARAL, M. H. do; MONTEIRO, M. I. B. Análise de obras cinematográficas para compreender as concepções de professores sobre o aluno com deficiência. Ver. Bras. Ed. Esp., Marilia, v. 22, n. 4, p. 511-526, out./dez. 2016a.

AMARAL, M. H. do; MONTEIRO, M. I. B. Deficiência e linguagem cinematográfica. Journal of Research in Special Educational Needs, v. 16, n. 1, p. 351-354, 20166.

BABEL. Direção: Alejandro González Iñárritu. Intérpretes: Brad Pitt, Cate Blanchett, Gael Garcia Bernal, Adriana Barraza, Rinko Kikuchi, Kôji Yakusho. EUA, México, França: Paramount Pictures, 2007.1 DVD (142 min), color. 
BRASIL, Lei no 10436, de 24 de abril de 2002. Dispõe sobre a Língua Brasileira de Sinais - Libras e dá outras providências. Diário Oficial da União: Brasilia, DF, 2002. Disponivel em: http://www.planalto.gov.br/ccivil_03/leis/2002//10436.htm. Acesso em: 10 out. 2021.

BRAZ, R. M. M. Libras: a construção e a divulgação dos conceitos científicos sobre o ensino de ciências e biotecnologia através da integração de um dicionário internacional online. 2014. 184f. Tese (Doutorado em Ciências e Biotecnologia) - Universidade Federal Fluminense, Niterói, 2014.

CARVALHO, P. V. Herança do Abade de L'Épée na viragem do século XVIII para o século XIX. Lisboa: The Factory, 2013.

COSTA, F. C. As ruidosas mulheres do cinema silencioso. In: HOLANDA, K. (org.). Mulheres de cinema. Rio de Janeiro: Numa, 2019. v. 1, p. 19-36.

DIZEU, L. C. T. B.; CAPORALLI, S. A. A língua de sinais constituindo o surdo como sujeito. Educ. Soc., Campinas, v. 26, n. 91, p. 583-597, 2005.

LACERDA, C. B. F. de. Um pouco da história das diferentes abordagens na educação dos surdos. Cad. Cedes, São Paulo, v. 19, n. 46, p. 68-80, 1998. Disponivel em: http://www.scielo.br/ scielo.php?script=sci_arttext\&pid=S0101-32621998000300007\&tng=pt\&nrm=iso. Acesso em: 31 mar. 2021.

LARRUSCAIN, I. O. dos S.; OLIVEIRA, M. A. F. O cinema como ferramenta de auxilio no processo ensino-aprendizagem. 2011. Trabalho de conclusão de curso (Especialização em Mídias na Educação) - Universidade Federal de Santa Maria, Santa Maria, 2011.

SAUSSURE, F. de. Curso de Linguística Geral. São Paulo: Cultrix, 1987.

UZAN, A. J. S.; OLIVEIRA, M. R. T.; LEON, I. A importância da língua brasileira de sinais (Libras) como língua materna no contexto da escola do ensino fundamental. In: ENCONTRO LATINO-AMERICANO DE INICIAÇÃO CIENTÍFICA, 12; ENCONTRO LATINO-AMERICANO DE PÓS-GRADUAÇÃO, 8., 2008, São José dos Campos. Anais [...]. São José dos Campos: Universidade do Vale do Paraíba, 2008. p. 1-4.

Recebido em junho de 2021. Aprovado em setembro de 2021. 